\title{
Predicting the Compressive Strength of Desert Sand Concrete Using ANN: PSO and Its Application in Tunnel
}

\author{
He Cai, ${ }^{1}$ Taichang Liao, ${ }^{1}$ Shaoqiang Ren, ${ }^{1}$ Shuguang Li $\mathbb{D},{ }^{1,2}$ Runke Huo ${ }^{\circ},{ }^{2}$ Jie Yuan, ${ }^{3}$ \\ and Wencui Yang ${ }^{3}$ \\ ${ }^{1}$ China Railway 20th Bureau Group Co., Ltd., Xi'an 710016, China \\ ${ }^{2}$ School of Civil Engineering, Xi'an University of Architecture and Technology, Xi'an 710055, China \\ ${ }^{3}$ School of Transportation Science and Technology, Harbin Institute of Technology, Harbin 150090, China
}

Correspondence should be addressed to Shuguang Li; lssgg2015@163.com

Received 25 September 2020; Revised 11 November 2020; Accepted 8 December 2020; Published 17 December 2020

Academic Editor: Song-He Wang

Copyright @ $2020 \mathrm{He}$ Cai et al. This is an open access article distributed under the Creative Commons Attribution License, which permits unrestricted use, distribution, and reproduction in any medium, provided the original work is properly cited.

Desert sand is one of the current research hotspots in alternative materials for concrete aggregates. In the process of practical application, compressive strength is an essential prerequisite for studying other properties. Based on the current research situation, a prediction technology of compressive strength of desert sand concrete (DSC) is proposed based on an artificial neural network (ANN) and a particle swarm optimization (PSO). The technology is a prediction model that adjusts the network architecture by using the PSO method based on the ANN optimization model. Water-binder ratio, sand ratio, replacement rate of desert sand, desert sand type, fly ash content, silica fume content, air content, and slump were selected as the neural network's inputs. The compressive strength data of 118 different combinations of influencing variables were tested to establish the dataset. The results show that the PSO method is efficient for the ANN in DSC compressive strength research. Furthermore, referring to this method, DSC is applied to the shotcrete of tunnels in construction engineering successfully, and the dust particle content during construction is evaluated.

\section{Introduction}

Growing infrastructure needs worldwide have created an unprecedented demand for concrete. Concrete production outpaces any other material's per capita production and has become a significant contributor to the carbon footprint [1]. As one of the necessary concrete components, the stock of sufficient aggregate resources for construction, mainly river sand, has sharply declined. Its mining activity exerts a disastrous impact on the environment $[2,3]$. Meanwhile, desertification is one of the most severe global eco-environmental degradation problems, impacting $25 \%$ of the total terrestrial area and more than 250 million people worldwide [4-7], especially for some places at the edge of the desert and which lack infrastructure. If desert sand is used to replace a portion of the fine aggregate to prepare concrete, not only will the desert resources be fully utilized, but also construction costs can be massively reduced. The replacement of traditional sand with desert sand may catalyze a revolution in the construction engineering industry because of its significant environmental, economic, and social benefits.

The technical application of desert sand for the highway sandy soil subgrade is relatively mature [8]. However, the understanding and application of desert sand for concrete are still limited. The research on desert sand concrete (DSC) is at the early stage, but many beneficial results have been achieved.

The current research on DSC mainly focuses on the physical and chemical properties of desert sand [9-11], the conventional properties of DSC [12-19], and ultra (very)fine aggregate concrete [20-22]. In these studies, the highfrequency research variables include replacement rate of desert sand, sand rate, etc. Although there are large differences in these current research results, it can be 
determined that replacement rate of desert sand will have a much smaller impact on strength compared to the waterbinder ratio.

Conventional concrete compressive strength prediction methods are mainly based on statistical analysis, which can be predicted by linear and nonlinear regression equations. However, choosing the appropriate regression equation requires skill and rich experience, and conventional regression methods for complex multivariate problems are even more difficult. To improve these research approaches and reduce the cost of testing materials and testing time, the model based on experimental data can predict the impact of DSC variables on concrete performance within a specific acceptable error range. Among the many prediction models, there is a model based on an artificial neural network (ANN), an artificial intelligence technology prediction model that can use existing data to complete the ANN model's modeling study to achieve strength prediction. The model is used by using input and output variables to reach the prediction goal without many input restrictions finally. The ANN can provide a feasible solution to difficult problems by conventional techniques, such as multiple linear regression. Some published studies have shown that after optimization, the ANN can find the complex and nonlinear relationship between the parameters affecting concrete properties, such as predicting the compressive strength of high-performance concrete [23-27] and recycled aggregate concrete [28-30] with a variety of complex components.

Technically, the ANN architecture is an expression of experience. In the process of concrete strength prediction simulation, any singular models such as BP or RBF network are prone to produce a high mean squared error (MSE). If there are too many variables, the accuracy of ANN prediction would be significantly affected. Therefore, we proposed an optimized ANN based on particle swarm optimization (PSO). The ANN and PSO can predict DSC's compressive strength under the combined action of 8 variables. As a result, this study is a pioneering work for using the ANN and PSO in predicting primary DSC performance and trying to use DSC in tunnel shotcrete, which is of great significance to more engineering applications.

\section{Materials and Experiments}

Here, 42.5 grade ordinary Portland cement and commercially available fly ash were used as a cementitious material in this study. The properties of the cement are shown in Table 1. The $5-20 \mathrm{~mm}$ continuous graded crushed limestone was used as a coarse aggregate. Polycarboxylate superplasticizer with a $28 \%$ water reduction rate, the rosin air-entraining agent with a $4.0 \%$ air content, was used to achieve the expected slump flow and air content of DSC. According to the needs of different specific scenarios, another target performance (workability and mechanical) was selected.

Fine aggregates were manufactured sand (prewashing) and desert sand, and the fineness modulus of manufactured sand was 3.0. The macroscopic appearance of all desert sands is shown in Figure 1. Four desert grains of sand from the Chinese areas of Kubuzi, Maowusu, Tengger, and Ulanbuh
TABLE 1: Performance of cement.

\begin{tabular}{lc}
\hline Performance & Results \\
\hline Density $\left(\mathrm{g} / \mathrm{cm}^{3}\right)$ & 3.12 \\
Water consumption for standard consistency (wt \%) & 27.3 \\
Initial setting time $(\mathrm{min})$ & 184 \\
Final setting time (min) & 305 \\
Volume stability & Qualified \\
Ignition loss (wt \%) & 1.21 \\
Compressive strength $(\mathrm{MPa})(3 \mathrm{~d})$ & 26.2 \\
Compressive strength $(\mathrm{MPa})(28 \mathrm{~d})$ & 47.8 \\
Flexural strength $(\mathrm{MPa})(3 \mathrm{~d})$ & 5.2 \\
Flexural strength $(\mathrm{MPa})(28 \mathrm{~d})$ & 8.0 \\
\hline
\end{tabular}

were used, with fineness modulus values of $0.27,0.30,1.03$, and 0.57 , respectively. The gradation curves of the manufactured sand and the desert sand are shown in Figure 2(a) (the horizontal axis is set as a logarithm). The particle size of the desert sand was smaller than that of the fine sand, and the manufactured sand was medium sand. The mineral composition, as analyzed by X-ray diffraction (XRD), is shown in Figure 2(b). The four types of desert sand's main mineral types and contents were almost the same as those of the river sand. They were significantly different from the minerals in the manufactured sand, consisting of calcium carbonate calcite. All four types of desert sand met the primary conditions of being chemically inert fillers.

According to the mix proportion in supplementary data, solid materials such as cement, fly ash, silica fume, fine aggregate (manufactured sand and desert sand), and coarse aggregate were added to the forced mixer with a single horizontal shaft and mixed for 30 seconds. The chemical additives and water were mixed until fresh concrete was obtained (approximately 3 minutes). A, B, C, and D present desert sand of Kubuzi, Maowusu, Tengger, and Ulanbuh. The slump and air content of fresh concrete were tested using the Chinese standard GB/T 50080-2016. LA-0316 was used to measure air content, and a slump cylinder was employed to measure slump. DSC compressive strength was tested using the Chinese standard GB/T 50081-2019 (equivalent to ASTM-C39) at the curing age of 28 days. The DY-3000 electro-hydraulic servo press tested the compressive strength. In these specimens, considering that different research backgrounds used samples of different sizes and shapes, all of the results (some examples are $100 \mathrm{~mm}$ cubic) were converted into equivalent $150 \mathrm{~mm}$ cubic compressive strength using conversion coefficients following guidelines of GB/T 50081-2019.

\section{The ANN-PSO Prediction Model}

The compressive strength of DSC under 118 mix proportions of 8 variables is summarized in a supplementary file. From the test data, it can be visually concluded that the water-binder ratio significantly affects the compressive strength results compared with other variables. Fly ash and silica fume can also serve active roles in DSC, as in other ordinary concrete. However, most of the factors are not easy to detect, and there may be more complex interactions between the elements. If we comprehensively consider this, 


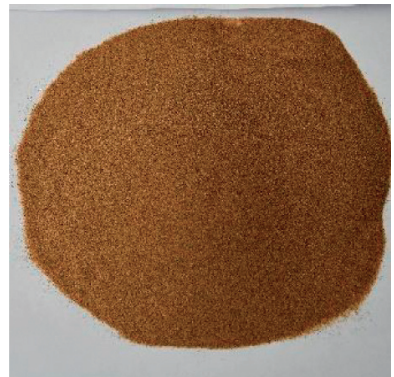

(a)

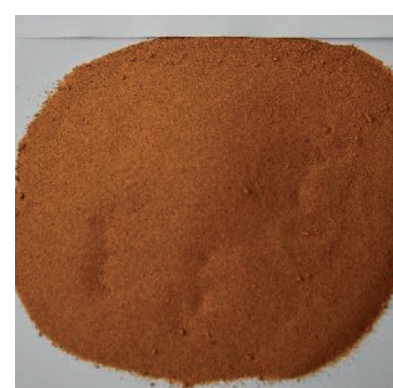

(b)

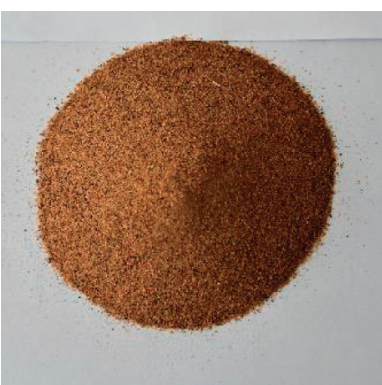

(c)

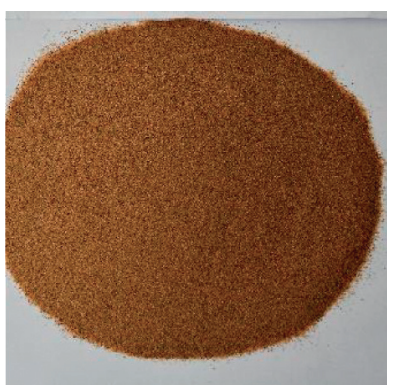

(d)

Figure 1: Four types of desert sand from different areas: (a) Kubuzi; (b) Maowusu; (c) Tengger; and (d) Ulanbuh.

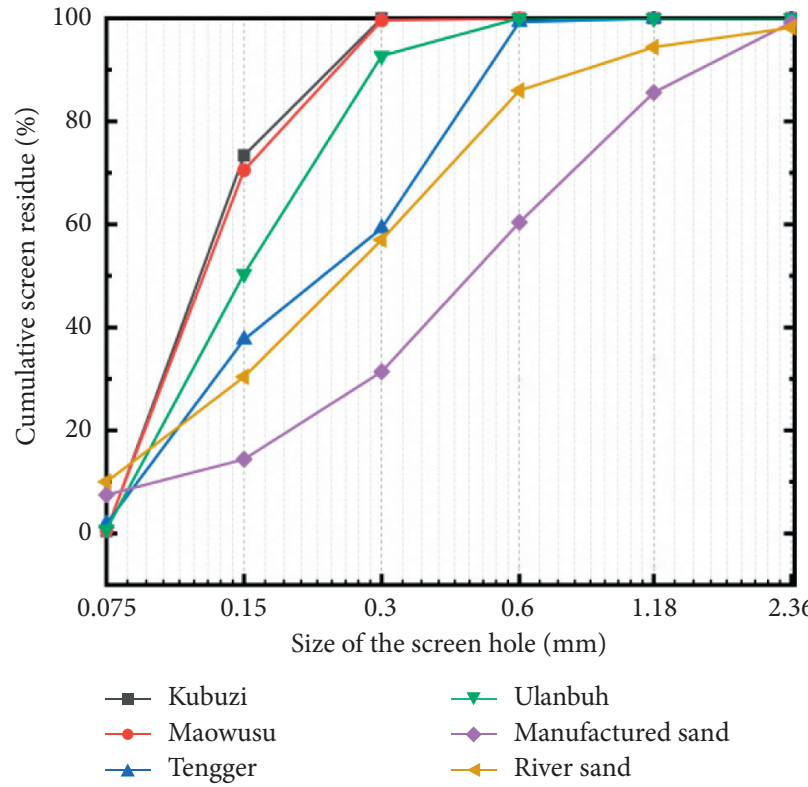

(a)

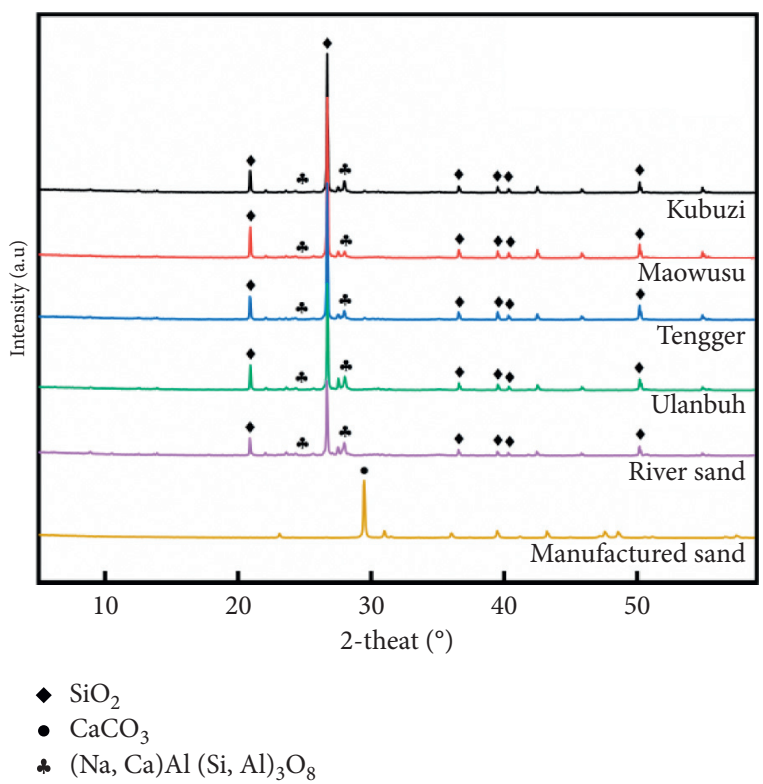

(b)

FIgURE 2: Comparison of characteristics among four kinds of desert sand and traditional sand used in this experiment. (a) Grading curve and (b) XRD.

even when using orthogonal testing, there will be vast amounts of experimentation and data. The conventional regression calculation cannot accurately and quantitatively describe the influence rules. Some of the test results are in line with this expectation, but the effective strength prediction cannot be achieved.

3.1. The ANN Method. The ANN is a mathematical or numerical model that simulates the functional biological neural aspects to obtain a computational paradigm that can map input and output [31]. Each neuron is a basic unit of calculation which performs the following equation:

$$
y=\max \left(0, \sum_{i} w_{i} x_{i}+b\right),
$$

where $y$ is the neuron output, $x_{i}$ is the neuron inputs, $w_{i}$ is the weight, and $b$ is deviation.
Each neuron yields a single output $(y)$ from all inputs $\left(x_{i}\right)$. All neurons are connected in a layered architecture [32], where the mapping between inputs and outputs is conducted using the following formula:

$$
\begin{aligned}
& h_{i}=\max \left(0, \mathbf{W}_{\mathbf{i}} \cdot \mathbf{h}_{\mathbf{i}-1}+\mathbf{b}_{\mathbf{i}}\right), \\
& y=\max \left(0, \mathbf{V} \cdot \mathbf{h}_{\mathbf{L}}\right),
\end{aligned}
$$

where $\mathbf{W}_{\mathbf{i}}$ and $\mathbf{V}$ are matrices, and $\mathbf{b}_{\mathbf{i}}$ is vectors that all parameters learned from the dataset; $L$ is the number of layers; and $1 \leq i \leq L, \mathbf{h}_{\mathbf{0}}=\mathbf{x}$.

In this case, the ANN input includes the normalized values of 8 variables, such as water-binder ratio, sand ratio, and replacement ratio of desert sand, and the output is the DSC's compressive strength value. All datasets are divided into two parts: the training set and the testing set. Ten-fold cross-validation is used as a verified method. In the 
beginning, the ANN architecture is optimized by PSO based on a mean squared error (MSE), which is defined as

$$
\operatorname{MSE}=\frac{1}{N} \sum_{i=1}^{N}\left(y_{i}^{*}-y_{i}\right)^{2},
$$

where $N$ is the number of data samples; $y_{i}^{*}$ and $y_{i}$ are the predicted value and test value of the data sample neural network, respectively.

$R$ is the correlation coefficient of the predicted value and test value, which is defined as

$$
R=\frac{\sum_{i=1}^{N}\left(y_{i}^{*}-\overline{y^{*}}\right)\left(y_{i}-\bar{y}\right)}{\sqrt{\sum_{i=1}^{N}\left(y_{i}^{*}-\overline{y^{*}}\right)^{2} \sqrt{\sum_{i=1}^{N}\left(y_{i}-\bar{y}\right)^{2}}}}
$$

3.2. The PSO Method. The PSO algorithm is based on a metaheuristic algorithm proposed by Eberhart [33]. It is a powerful optimization technique that can be used to find the optimal global value in a multidimensional search space [34]. Combined with the PSO algorithm, the ANN has high robustness and stability and can effectively realize the demand for obtaining a panoramic view of data using fewer data. The MSE is used to evaluate the fitness of the particle position on training and testing sets. Thus, an ANN architecture that achieves a lower MSE will be represented by a particle with higher fitness. The next particle swarm is generated by updating the particle position. The PSO algorithm considers the best position of the particle swarm in history and each particle's best position in history. The particle swarm gradually moves to the best position until it reaches the target, such as maximum iteration times.

In the process of searching for the optimal value of space dimension $D$, a swarm is formed by $m$ particles, and the position of the $i$-th ion is recorded as $X_{i}=\left(x_{i}^{1}, x_{i}^{2}, \ldots, x_{i}^{D}\right)$. Each particle is a possible potential solution; $X_{i}$ is substituted into the objective function to calculate the fitness value of the particle, and the quality of the particle is measured according to the size of the fitness value. The best positions of particles are recorded as $p_{\text {best }, i}=\left(p_{\text {best }, i}^{1}, p_{\text {best }, i}^{2}, \ldots, p_{\text {best }, i}^{D}\right)$ and those of swarms are recorded as $g_{\text {best }, i}=\left(g_{\text {best }, i}^{1}, g_{\text {best }, i}^{2}, \ldots, g_{\text {best }, i}^{D}\right)$, and the velocity of particle $i$ is recorded as $v_{i}=\left(v_{i}^{1}, v_{i}^{2}, \ldots, v_{i}^{D}\right)$. In this case, the formula used for the particle-position update is

$$
\begin{aligned}
& V_{i}^{t+1}=w V_{i}^{t}+c_{1} r_{1}\left(p_{\text {best }, i}^{t}-X_{i}^{t}\right)+c_{2} r_{2}\left(g_{\text {best }, i}^{t}-X_{i}^{t}\right), \\
& X_{i}^{t+1}=X_{i}^{t}+X_{i}^{t+1},
\end{aligned}
$$

where $V_{i}^{t+1}$ and $V_{i}^{t}$ are the velocities of particle $i$ at iterations $t$ to $t+1 ; X_{i}^{t+1}$ and $V_{i}^{t}$ are positions of particle $i$; $w$ is weight; $c_{1}$ and $c_{2}$ are parameters of cognitive influence and social influence; and $r_{1}$ and $r_{2}$ are random values between 0 and 1 .

3.3. Dataset Construction. The experimental data collected between March 2019 and June 2020 were selected. In this term, raw materials such as cement, fly ash, and additives are stable and controllable. The mix proportion range is shown in Table 2. A total of 118 groups of DSC samples of different mix proportions were prepared. Each experiment was repeated three times, and the dataset of the ANN model was constructed using the average compressive strength values as the output. None of the test results are out of tolerance. Water-binder ratio, sand ratio, replacement rate of desert sand, desert sand type, fly ash content, silica fume content, air content, and slump were selected as the ANN variables (inputs). For the input variable of desert sand type, its normalization is realized by transforming text values into four-dimensional unit vectors, and its form is as follows:

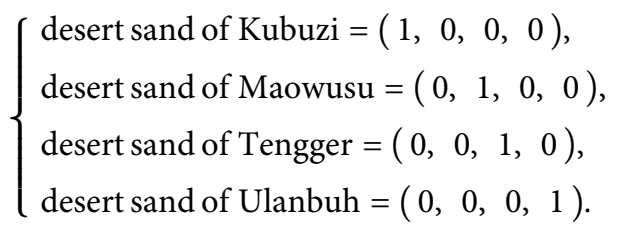

Other discounts are input after the min-max normalization method. The replacement of desert sand interval of 10 wt $\%$ is used, where 0 wt $\%$ is pure manufactured sand concrete, and $100 \mathrm{wt} \%$ is pure desert sand concrete. Fly ash is selected according to different water-binder ratios. Silica fume is only mixed in the case of a low water-binder ratio. The suitable workability is achieved by adjusting water consumption and admixtures, and the air content and slump are used to characterize its effect. The target data of air content and slump are $4.0 \%$ and $195 \mathrm{~mm}$, and their actual data are used as input variables. From these 118 groups of DSC data, 15 groups of data are selected as a testing set, and the rest are the training set.

\section{Results of ANN-PSO}

4.1. Selection of Model Parameters. The numbers of hidden layers (Num hidden) and neurons (Num neuron) need to be adjusted in the PSO optimization algorithm. There is no specific technique to evaluate the number of neurons in the hidden layer of networks, and trial and error should be used. According to experimental adjustment and experience, the number of hidden layers is $1-3$, the adjustment range of the number of neurons is $2-15$, and the maximum number of iterations is selected as 1,200. Figure 3 shows the swarm minimum MSE values (corresponding to best swarm positions) versus iteration when several parameter schemes with stable iteration are chosen. The iteration effect of the No. G scheme is the best, including two hidden layers with ten neurons in layer No. 1 and 2 neurons in layer No. 2. Thus, the values of parameters used in this research are as follows:

$$
\begin{aligned}
& \text { Number of input layer units }=11 \\
& \text { Number of hidden layers }=2 \\
& \text { Number of hidden layer } 1 \text { neurons }=10 \\
& \text { Number of hidden layer } 2 \text { neurons }=2 \\
& \text { Number of output layer units }=8 \\
& \text { Number of particles in swarm }=40 \\
& \text { Learning rate }=0.3 \\
& c_{1}=1.49445 \\
& c_{2}=1.49445
\end{aligned}
$$


TABLE 2: Range of input and output parameters in the database.

\begin{tabular}{lcc}
\hline Input parameters & Minimum & Maximum \\
\hline Water-binder ratio & 0.24 & 0.50 \\
Sand ratio (wt \%) & 24 & 46 \\
The replacement rate of desert sand & 0 & 100 \\
(wt \%) & - & - \\
Desert sand type & 10 & 25 \\
Fly ash content (wt \%) & 0 & 10 \\
Silica fume content (wt \%) & 2.8 & 6.3 \\
Air content (vol\%) & 125 & 235 \\
Slump (mm) & 32.8 & 86.2 \\
Output value (MPa) (28 d) & &
\end{tabular}

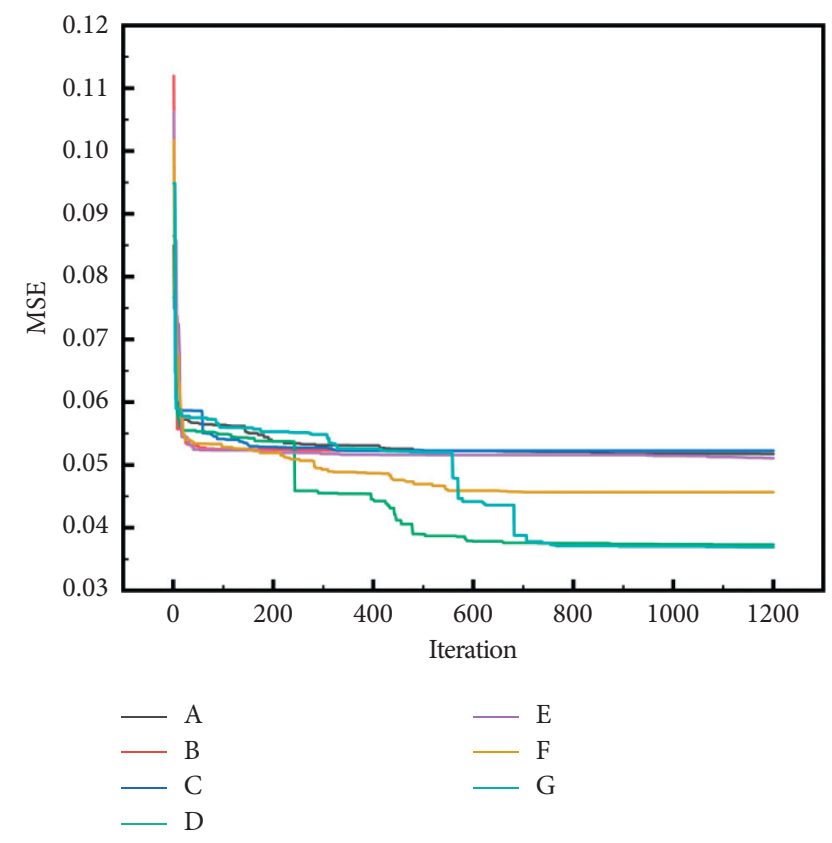

Figure 3: Selection of modeling parameter schemes.

Number of iterations $=1,200$

After iteration, the MSE decreases significantly, which shows that PSO can realize the architecture optimization of the ANN. The MSE converges gradually as the number of iterations approaches 1,200. The optimum ANN architecture used for further analysis is illustrated in Figure 4.

4.2. ANN Architecture Optimization Results. By comparing the predicted value with the experimental value, it can be seen that the ANN-PSO technology exerts a positive effect on DSC's strength prediction. In Figure 5, DSC's compressive strength values are predicted by the ANN-PSO model versus the experimental values in training set and testing set, respectively. By using the MSE (Figure 3) and the correlation coefficient (R) (Figures $5(\mathrm{~b})$ and $5(\mathrm{~d})$ ) to characterize the performance of the ANN-PSO model, it can be seen that the complicated simulated relationship between input and output can be realized $(\mathrm{MSE}=0.037)$. For the 103 data training, the correlation coefficient (R) between predicted and experimental values was 0.948 , and it was 0.977 for the testing set of 15 data. Compared with the training set and the testing set, the ANN-PSO model results confirm that it was well-trained, and this parameter selection can properly avoid underfitting and overfitting.

\section{Application of DSC in the Tunnel with the ANN-PSO Method}

5.1. Background of Engineering Application. Bid TJ-1 of Wuhua expressway is located between Wuqi County and Zhidan County in Yan'an, Shaanxi Province, China, with a total length of $10.165 \mathrm{~km}$. There are three tunnels in this project, all of which go straight through the old loess. The tunnels' surrounding rock is mainly composed of clay minerals such as illite and montmorillonite, mixed with detrital minerals such as quartz, typical in the northwest of China [35-37]. There are many layers of paleo soil in the surrounding rock with scattered calcareous nodules, and the earth is loosed. The construction volume of C25 shotcrete in all three tunnels reaches $43304 \mathrm{~m}^{3}$, of which $15760 \mathrm{~m}^{3}$ is prepared with desert sand in testing. Due to the low strength of design and preliminary study, at this strength level, the replacement rate of desert sand could be selected as high as possible based on the economic principle.

5.2. DSS with the ANN-PSO Method. Desert sand collected from the natural desert of Maowusu (near the Jingbian County) and other materials and experimental methods are the same as "Materials and Experiments" mentioned above. The DSS is prepared with the preset water-binder ratio, sand ratio, replacement rate of desert sand, desert sand type, and fly ash content. In the actual test of shotcrete, the air content is controlled between $2.0 \%-4.0 \%$ and the slump between $130 \mathrm{~mm}-150 \mathrm{~mm}$ by adjusting admixture proportion in Section 2 using existing data as input data.

Four kinds of DSS proportions with high-content desert sand and one contrast, ordinary sand shotcrete (DSS) proportion of only manufactured sand but not desert sand were selected. Input new data in Table 3 into the ANN-PSO model deduced above, and predicting $28 \mathrm{~d}$ compressive strength is the model calculation's output value.

Figure 6 shows the ANN-PSO model predicted value and real test value for the DSS mix proportion. Here, the data of the real test are mean \pm s.e.m. of the indicated number of independent experiments. One-sample $t$-tests are used to test for difference between the value of ANN-PSO simulation and the real test. The discreteness of DSS strength values has interference to judgment initially. However, where nine groups (27 repeated tests) of specimens are selected for each mix proportion, strength trend and model prediction have a certain degree of similarity. Three of the five groups have $P>0.05$, and the predicted values of the other two groups' predicted values also fell into the extreme value range. At this strength level, even when the accelerator is added; the $28 \mathrm{~d}$ strength of DSS still has a large surplus and meets the strength requirements of shotcrete. This result provides a fundamental guarantee for the application of DSS. DSS-3 mix proportion is selected as the DSS application eventually. 


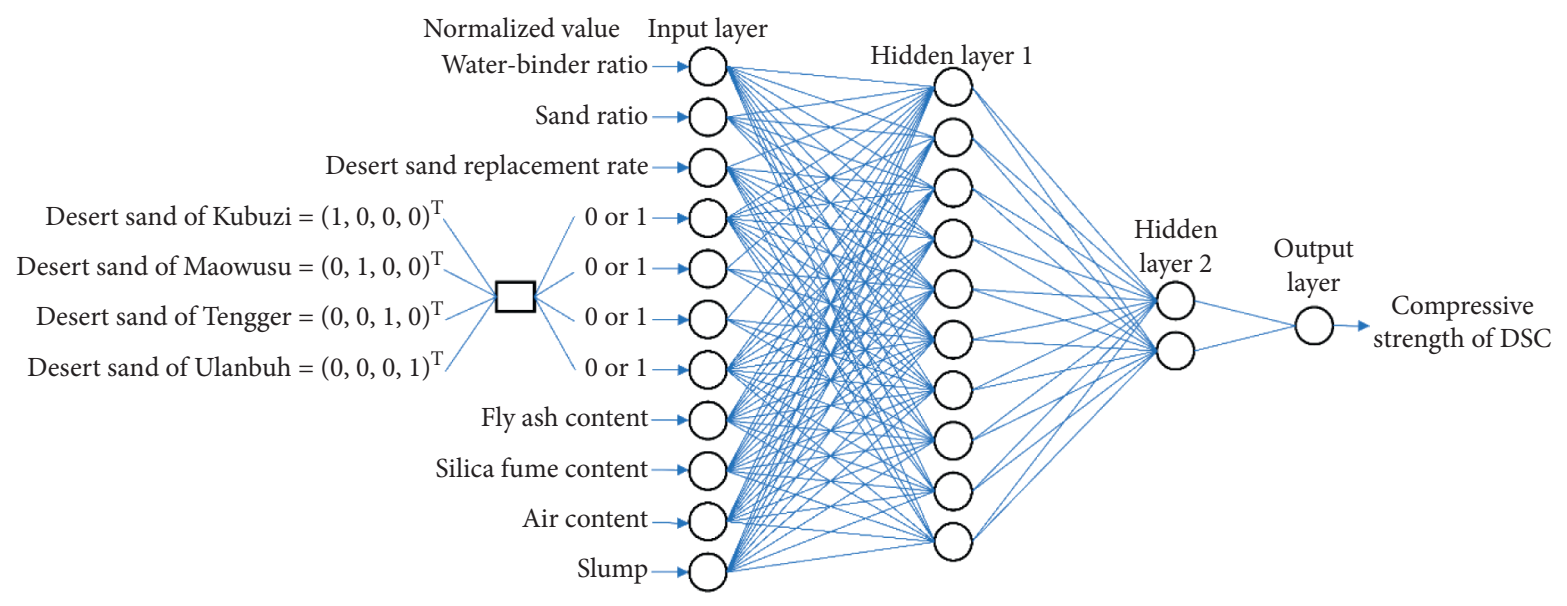

FIGURE 4: Architecture of the model.

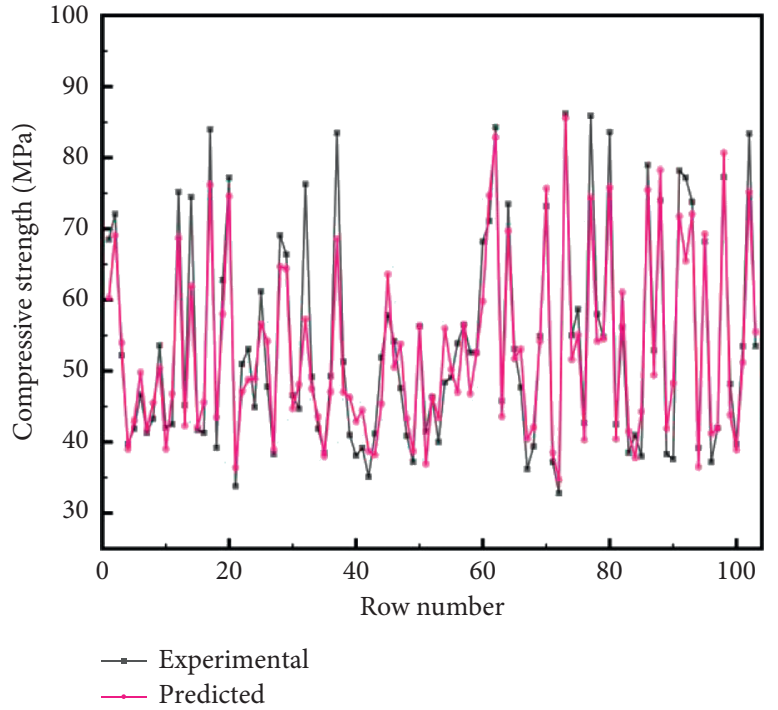

(a)

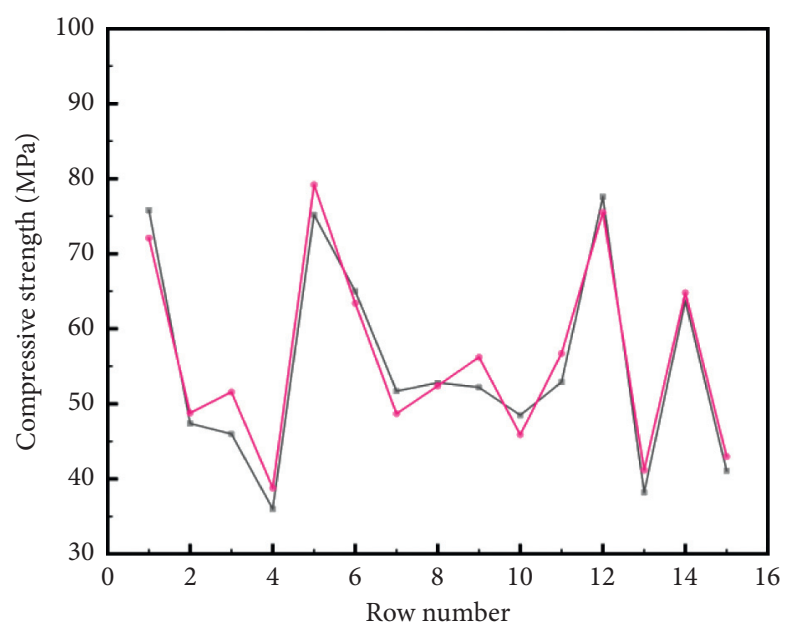

$\rightarrow$ Experimental

$\longrightarrow$ Predicted

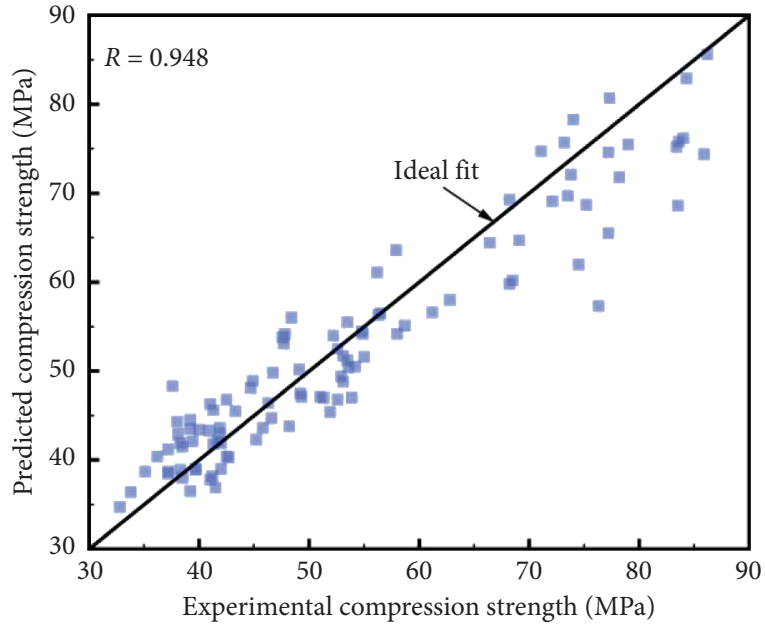

(b)

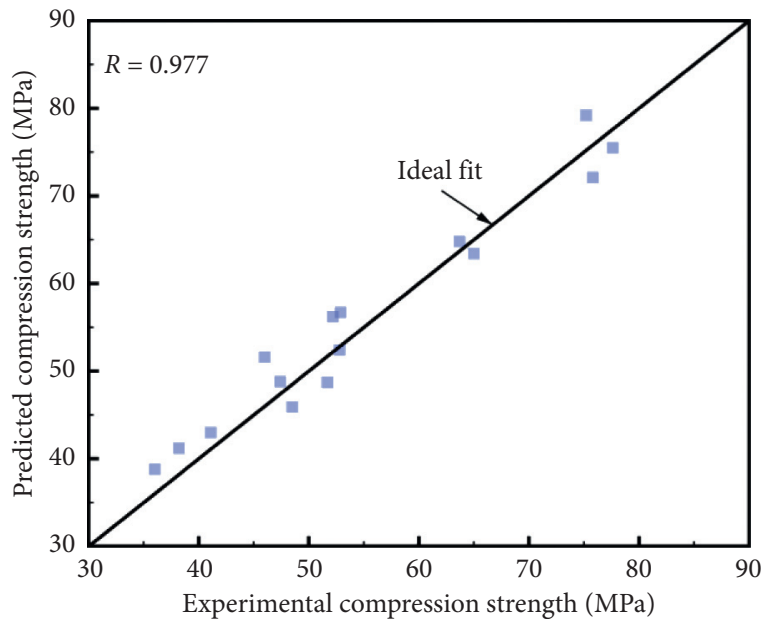

(d)

Figure 5: Comparison of predicted and experimental values. (a, b) Comparison on the training set. (c, d) Comparison on the testing set. 
TABLE 3: Mix proportion of shotcrete for testing.

\begin{tabular}{lccccccccc}
\hline Number & $\begin{array}{c}\text { Water- } \\
\text { binder } \\
\text { ratio }\end{array}$ & $\begin{array}{c}\text { Sand } \\
\text { ratio } \\
\text { (wt \%) }\end{array}$ & $\begin{array}{c}\text { The replacement } \\
\text { rate of desert sand } \\
\text { (wt \%) }\end{array}$ & $\begin{array}{c}\text { Desert } \\
\text { and type }\end{array}$ & $\begin{array}{c}\text { Fly ash } \\
\text { content } \\
\text { (wt \%) }\end{array}$ & $\begin{array}{c}\text { Silica fume } \\
\text { content } \\
\text { (wt \%) }\end{array}$ & $\begin{array}{c}\text { Air } \\
\text { content } \\
\text { (vol \%) }\end{array}$ & $\begin{array}{c}\text { Slump } \\
\text { (mm) }\end{array}$ & $\begin{array}{c}\text { Predicting of 28d } \\
\text { compressive } \\
\text { strength (MPa) }\end{array}$ \\
\hline OSS & 0.42 & 46 & 0 & B & 10 & 0 & 2.8 & 140 & 43.4 \\
DSS-1 & 0.42 & 40 & 80 & B & 10 & 0 & 2.3 & 135 & 39.5 \\
DSS-2 & 0.42 & 40 & 80 & B & 10 & 0 & 3.1 & 140 & 42.8 \\
DSS-3 & 0.42 & 40 & 100 & B & 10 & 0 & 3.4 & 140 & 40.9 \\
DSS-4 & 0.44 & 40 & 100 & B & 10 & 0 & 3.7 & 140 & 40.3 \\
\hline
\end{tabular}

Note. The desert sand type B means desert sand of Maowusu.

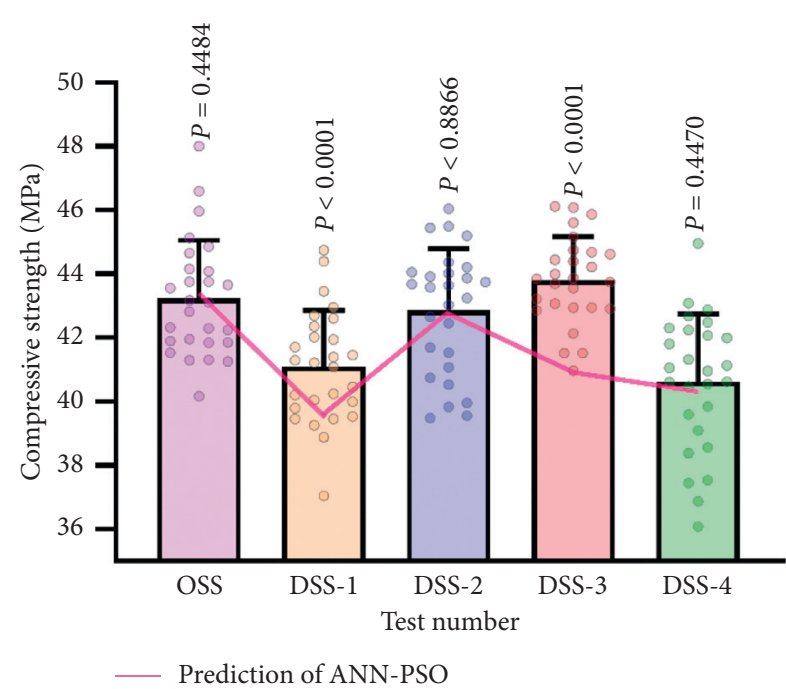

FIgURE 6: Comparison of the ANN-PSO model predicted value and actual test value.

With suggestions based on being environment friendly [38], the wet shotcrete construction method is the only method in this study. Alkali accelerator was added in DSS proportion according to $5 \%$ of the total cementitious material. The design strength is $\mathrm{C} 25$, and the $1 \mathrm{~d}$ strength is $\geq 10 \mathrm{MPa}$ in this construction engineering.

The standard cross section of the testing tunnel is shown in Figure 7(a). After the construction of DSS shotcrete (Figures 7(b) and 7(c)) and the curing age of 24h, the tests followed up. Figure 7(d) shows a rapid and straightforward method to determine the strength of shotcrete using the nail shooting method as the Chinese standard TB 10426, equivalent to the method of Hilti gun/bolt driving [39]. Still, the result of $13.6 \mathrm{MPa}$ is only for preliminary reference. Furthermore, the $1 \mathrm{~d}$ strength of cutting specimens of a shotcrete slab is $14.1 \mathrm{MPa}$ and $32.9 \mathrm{MPa}$ for $28 \mathrm{~d}$ (testing method as the Chinese standard JGJ/T 372). The results fully meet the design requirements and even have high residual strength.

5.3. Environmental Evaluation in the Construction Site. In some working areas, respirable dust concentrations of shotcrete construction with poor conditions are far more than any environmental standard [40-42]. Dust poses a risk to the human respiratory system, which needs to be controlled to fulfill health and safety standards and provide a safe work environment [38, 43-45]. In DSS, it might have some unknown effects between desert sand of small particle size and cement slurry, resulting in the change of dust amount in the construction environment. Therefore, respirable dust concentration detection is required.

The change of dust particles during DSS operation was detected to evaluate the impact of the working environment on workers' health in the DSS construction site. The OSS (100\% manufactured sand as fine aggregate) and DSS-3 (100\% desert sand as fine aggregate) mix proportion in Table 3 were selected. With $5 \%$ of the total amount of cementitious materials, an alkali accelerator was added in two mix proportions. The comparative environmental tests were carried out on the shotcrete with two mixed ratios. PM1.0, PM2.5, and PM10 values for the shotcrete working face were measured by Dark Eagle 9600 type dust particle counters.

Firstly, 5-8 meters were chosen as the distance between the nozzle and ten dust particle counters (the number of repetitions is 10), and automatic detection was set [42]. Secondly, we detected the number of environmental dust particles in the working face before and during construction. When shotcrete operation reached a stable condition, the current readings of PM1.0, PM2.5, and PM10 were recorded. Finally, the difference of the dust particle number of the two proportions under the different tunnels was compared (two different tunnels with the same size as the working face, Figure 7(a)).

Before shotcrete construction, the DSS-3 mix proportion always has fewer dust particles than OSS. Considering that dust particle accumulation may be caused by other factors such as continuous construction, the difference between dust particles before and during construction is selected as the comparison factor. Figure 8 shows that desert sand has a significant impact on the dust concentration difference of shotcrete construction. Before and during construction, the dust particle concentration is significantly affected. During construction, the dust particle concentration is considerably higher than before, irrespective of DSS-3 or OSS mix proportion. Additionally, both DSS-3 and OSS have a significant increase in all types of dust particles, and the rise of PM10 is more significant than that of PM2.5 and PM1.0.

Although desert sand significantly reduces the particle concentration in the shotcrete construction environment, the construction site still has a very high particle concentration. It is suggested that the construction personnel 


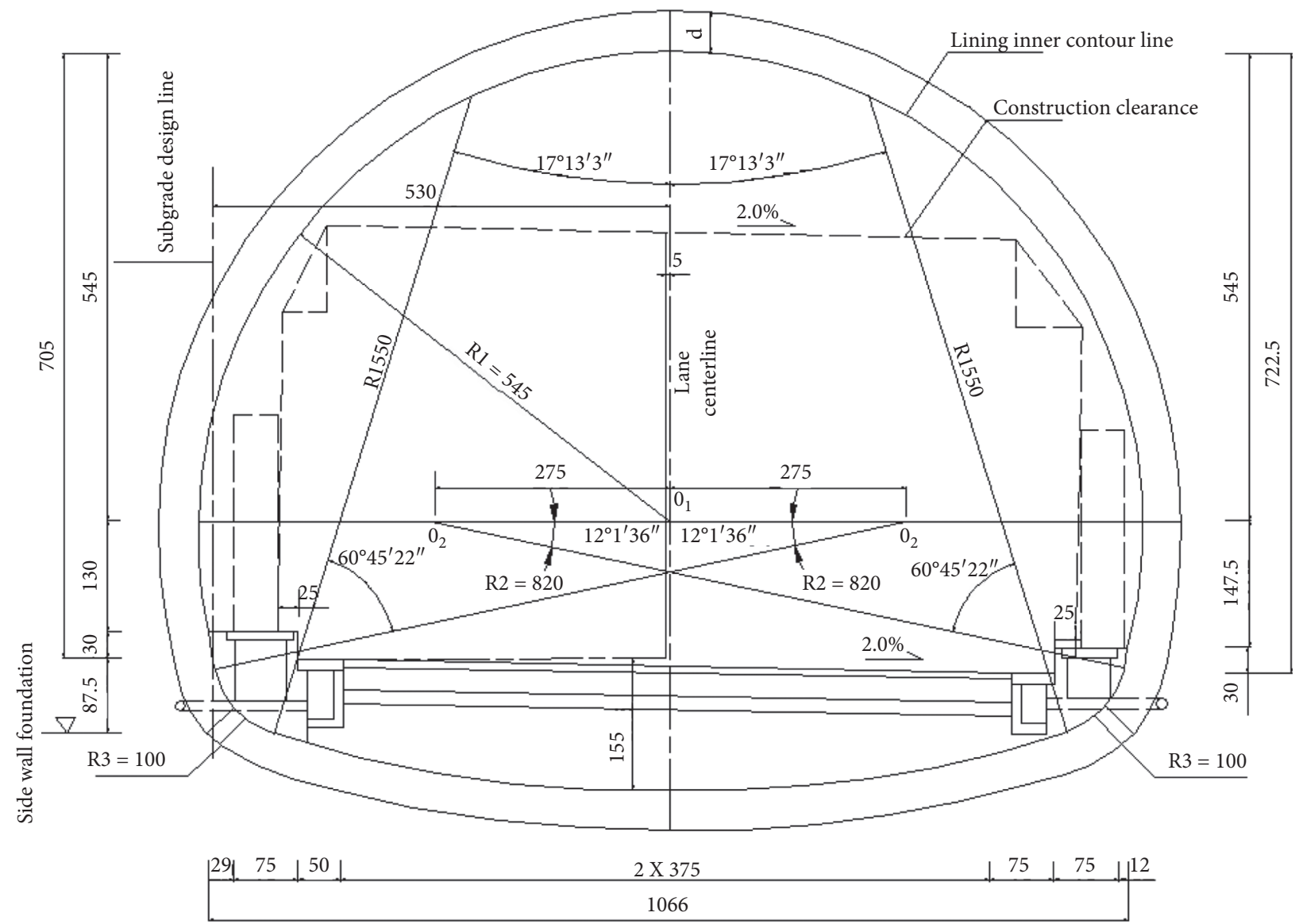

(a)

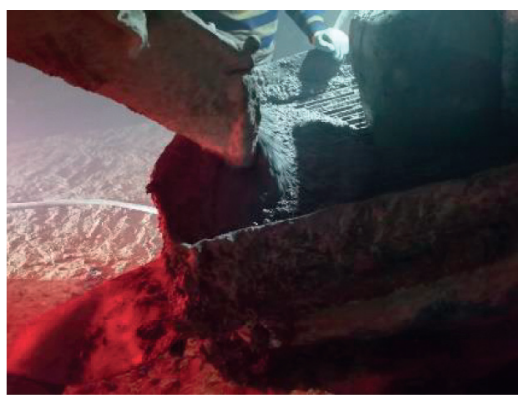

(b)

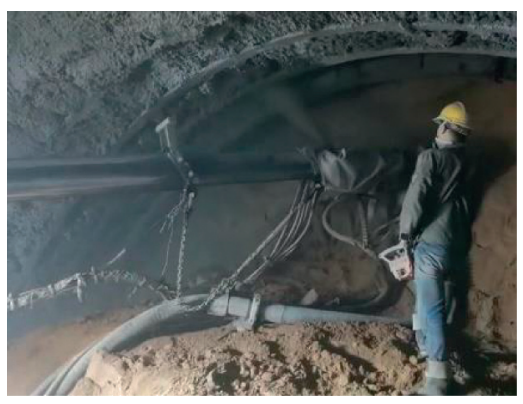

(c)

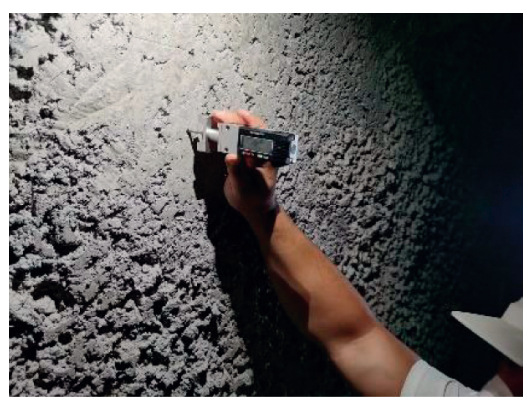

(d)

FIGURE 7: On-site construction process of DSS. (a) The standard cross section of the tunnel in the test section; (b) workability of DSS; (c) process of the wet spraying method; (d) reference of the nail shooting method for $1 \mathrm{~d}$ strength testing. 


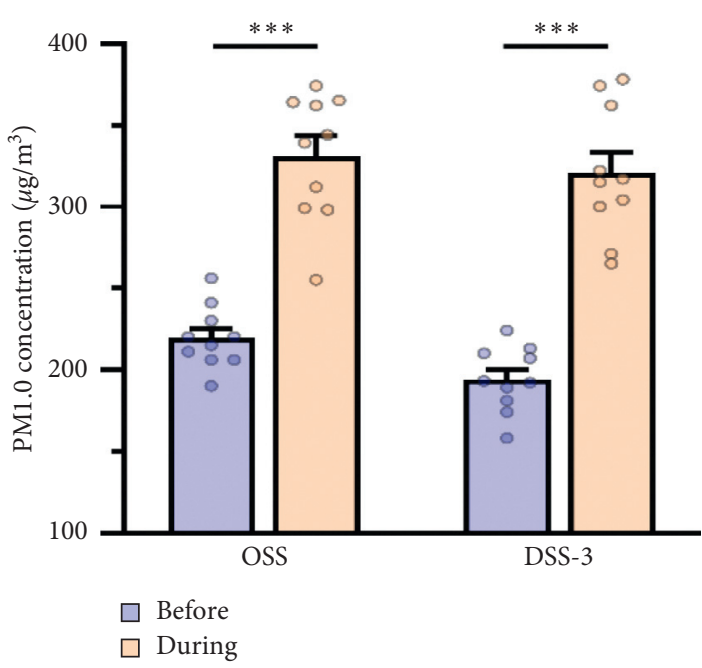

(a)

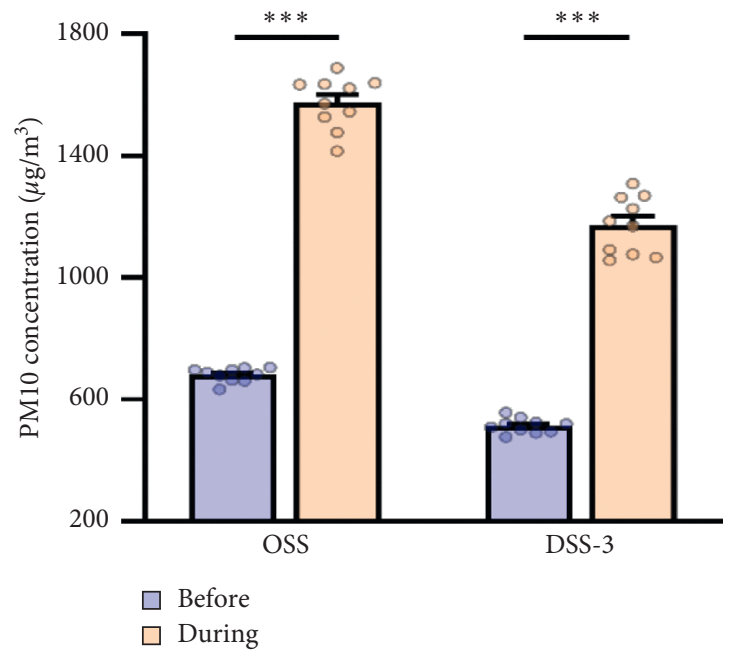

(c)

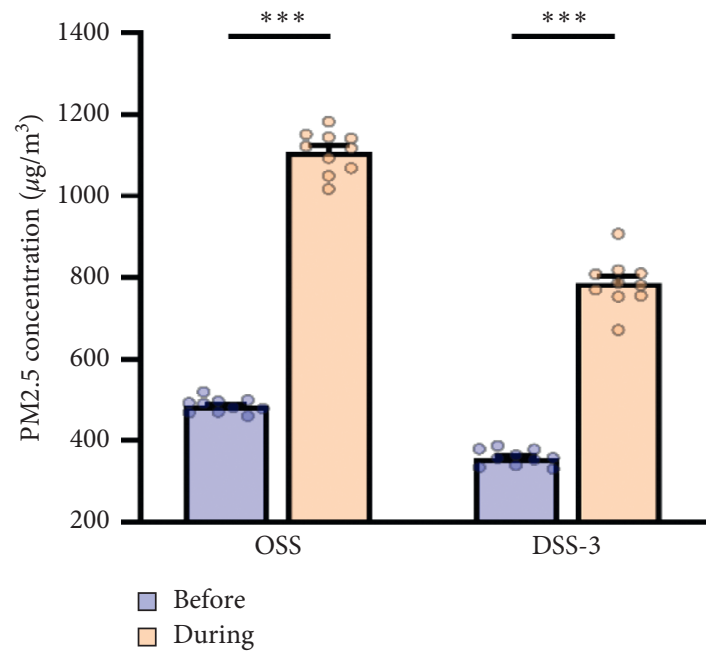

(b)

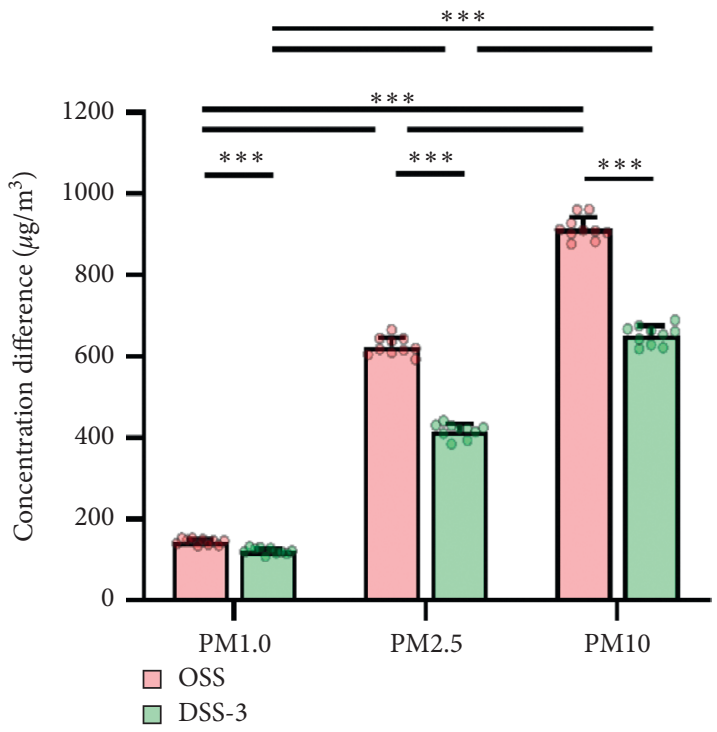

(d)

FIGURE 8: Comparison of dust particles before and during shotcrete construction with two mix proportions. (a) PM1.0 concentration; (b) PM2.5 concentration; (c) PM10 concentration; (d) concentration difference of dust particles before and during shotcrete construction. Data are mean \pm s.e.m. of the indicated number of independent experiments. ${ }^{*} P<0.05,{ }^{* *} P<0.01$, and ${ }^{* * *} P<0.001$. One-way ANOVA determined $P$ values with Tukey's multiple comparison post hoc test.

should ensure that the protective equipment is worn during DSS construction to prevent health hazards.

5.4. Advantages and Limitations of the Model. The research's main aim is to verify the correctness of the prediction of the DSC's compressive strength by the ANN and PSO method. Compared with ordinary methods, the ANN and PSO offer the advantages of conserving workforce and material resources, reducing time consumption, and providing nondestructive testing. Compared with conventional multiple linear regression and traditional ANN algorithms, PSO and ANN methods exhibit higher robustness and stability, effectively satisfying the demand for obtaining the data panorama with less information. It is more convenient to establish and update the general model. Meanwhile, DSC's successful application in shotcrete in tunnel shows that desert sand, a neglected material, has an extraordinary value and is of great significance to infrastructure construction.

However, due to experimental conditions' limitations, complete and quantitative physicochemical characteristics of desert sand cannot be obtained in this study. Therefore, this paper uses converting text into vectors to simplify the input of desert sand characteristics. An ANN model with a more remarkable inductive ability can be obtained after clarifying the materialized factors.

In terms of application, the durability of DSC for shotcrete construction needs to be tested in time. We will follow up with further research and publish valuable information at the right time and try to apply DSC in more 
scenarios. Besides, the application of DSC is still a very challenging task. We hope that this pioneering work can inspire more peer researchers to carry out more detailed and in-depth research in this direction.

\section{Conclusion}

(1) The technology based on ANN and PSO was utilized to predict DSC's compressive strength with 118 experimental datasets. Eight variables were selected as the inputs of the ANN. The maximum number of iterations was 1,200 . The correlation coefficient between the predicted test value and the training set is 0.948 . The correlation coefficient with the test set is 0.977 , both of which exhibit high correlation, indicating that the ANN-PSO prediction model achieves high accuracy in predicting desert sand concrete strength. Based on a certain amount of learning data, the results show that the ANN-PSO method proposed in this paper can be used to intelligently and quickly predict the compressive strength of DSC.

(2) When DSC is applied in shotcrete, even the replacement rate reaches $100 \%$; it still achieves sound initial and medium-term effects, and DSC dramatically reduces the content of dust particles in the construction environment under the wet shotcrete construction technology. However, it is still necessary to wear protective equipment at the construction site.

\section{Data Availability}

The data included in this study are available from the corresponding author upon request.

\section{Conflicts of Interest}

The authors declare no conflicts of interest.

\section{Acknowledgments}

This research was funded by the Science and Technology Research and Development Plan of China Railway Construction Co., Ltd. (2019-B07), China Postdoctoral Science Foundation (2020M673525), and China Railway 20th Bureau Group Co., Ltd. (YF2000SD01A).

\section{References}

[1] E. del Rey Castillo, N. Almesfer, O. Saggi, and J. M. Ingham, "Light-weight concrete with artificial aggregate manufactured from plastic waste," Construction and Building Materials, vol. 265, Article ID 120199, 2020.

[2] M. Bendixen, J. Best, C. Hackney, and L. L. Iversen, "Time is running out for sand," Nature, vol. 571, no. 7763, pp. 29-31, 2019.

[3] P. J. M. Monteiro, S. A. Miller, and A. Horvath, "Towards sustainable concrete," Nature Materials, vol. 16, no. 7, pp. 698-699, 2017.

[4] K. Qiu, Y. Xie, D. Xu, and R. Pott, "Ecosystem functions including soil organic carbon, total nitrogen and available potassium are crucial for vegetation recovery," Scientific Reports, vol. 8, no. 1, pp. 1-11, 2018.

[5] C. Noyola-Medrano and V. A. Martínez-Sías, "Assessing the progress of desertification of the southern edge of chihuahuan desert: a case study of san luis potosi plateau," Journal of Geographical Sciences, vol. 27, no. 4, pp. 420-438, 2017.

[6] G. R. H. Allington and T. J. Valone, "Reversal of desertification: the role of physical and chemical soil properties," Journal of Arid Environments, vol. 74, no. 8, pp. 973-977, 2010.

[7] J. F. Reynolds, D. M. S. Smith, E. F. Lambin et al., "Global desertification: building a science for dryland development," Science, vol. 316, no. 5826, pp. 847-851, 2007.

[8] C. Jin, Z. Dong, and Z. Li, "Construction techniques for the Taklamakan Desert Highway: research on the construction materials and the results of field tests," Environmental Geology, vol. 49, no. 6, pp. 915-922, 2006.

[9] L. Chen, W. Yu, C. Yang, X. Yi, and W. Liu, "Conductivity of aeolian sand on the Tibetan Plateau based on microstructure," Environmental Geology, vol. 36, pp. 1220-1226, 2014.

[10] J. F. Kok, E. J. Parteli, T. I. Michaels, and D. B. Karam, "The physics of wind-blown sand and dust," Reports on Progress in Physics Physical Society, vol. 75, no. 10, Article ID 106901, 2012.

[11] S. Guerzoni, E. Molinaroli, and R. Chester, "Saharan dust inputs to the W. Mediterranean Sea: depositional patterns, geochemistry and sedimentological implications," Deep-Sea Research, vol. 44, no. 3-4, pp. 631-654, 1997.

[12] E.-S. S. A. Seif, "Assessing the engineering properties of concrete made with fine dune sands: an experimental study," Arabian Journal of Geosciences, vol. 6, no. 3, pp. 857-863, 2013.

[13] Y. Li, H. Zhang, G. Liu, D. Hu, and X. Ma, "Multi-scale study on mechanical property and strength prediction of aeolian sand concrete," Construction and Building Materials, vol. 247, Article ID 118538, 2020.

[14] L. Haifeng, M. Jurong, W. Yiying, and N. Jianguo, "Influence of desert sand on the mechanical properties of concrete subjected to impact loading," Acta Mechanica Solida Sinica, vol. 30, no. 6, pp. 583-595, 2017.

[15] W. Yan, G. Wu, and Z. Dong, "Optimization of the mix proportion for desert sand concrete based on a statistical model," Construction and Building Materials, vol. 226, pp. 469-482, 2019.

[16] W. Dong, X.-D. Shen, H.-J. Xue, J. He, and Y. Liu, "Research on the freeze-thaw cyclic test and damage model of Aeolian sand lightweight aggregate concrete," Construction and Building Materials, vol. 123, no. 1, pp. 792-799, 2016.

[17] J. Jiang, T. Feng, H. Chu et al., "Quasi-static and dynamic mechanical properties of eco-friendly ultra-high-performance concrete containing aeolian sand," Cement and Concrete Composites, vol. 97, pp. 369-378, 2019.

[18] J. Kaufmann, "Evaluation of the combination of desert sand and calcium sulfoaluminate cement for the production of concrete," Construction and Building Materials, vol. 243, Article ID 118281, 2020.

[19] H. Chu, F. Wang, L. Wang, T. Feng, and D. Wang, "Mechanical properties and environmental evaluation of ultrahigh-performance concrete with aeolian sand," Materials, vol. 13 , no. 14 , p. $3148,2020$.

[20] A. Kronlöf, "Effect of very fine aggregate on concrete strength," Materials and Structures, vol. 27, no. 1, pp. 15-25, 1994. 
[21] F. J. Luo, L. He, Z. Pan, W. H. Duan, X. L. Zhao, and F. Collins, "Effect of very fine particles on workability and strength of concrete made with dune sand," Construction and Building Materials, vol. 47, pp. 131-137, 2013.

[22] A. S. Al-Harthy, M. A. Halim, R. Taha, and K. S. Al-Jabri, "The properties of concrete made with fine dune sand," Construction and Building Materials, vol. 21, no. 8, pp. 1803-1808, 2007.

[23] H. Mashhadban, S. S. Kutanaei, and M. A. Sayarinejad, "Prediction and modeling of mechanical properties in fiber reinforced self-compacting concrete using particle swarm optimization algorithm and artificial neural network," Construction and Building Materials, vol. 119, pp. 277-287, 2016.

[24] D.-K. Bui, T. Nguyen, J.-S. Chou, H. Nguyen-Xuan, and T. D. Ngo, "A modified firefly algorithm-artificial neural network expert system for predicting compressive and tensile strength of high-performance concrete," Construction and Building Materials, vol. 180, pp. 320-333, 2018.

[25] S. Chithra, S. R. R. S. Kumar, K. Chinnaraju, and F. Alfin Ashmita, "A comparative study on the compressive strength prediction models for High Performance Concrete containing nano silica and copper slag using regression analysis and Artificial Neural Networks," Construction and Building Materials, vol. 114, pp. 528-535, 2016.

[26] L. Chengyao, Q. Chunxiang, C. Huaicheng, and K. Wence, "Prediction of compressive strength of concrete in wet-dry environment by BP artificial neural networks," Advances in Materials Science and Engineering, vol. 2018, pp. 1-11, 2018.

[27] C. Palika, S. R. Kumar, and K. Maneek, "Prediction of compressive strength of concrete using artificial neural network and genetic programming," Advances in Materials Science and Engineering, vol. 2016, pp. 1-10, 2016.

[28] S. Kim, H. B. Choi, Y. Shin, G. H. Kim, and D. S. Seo, "Optimizing the mixing proportion with neural networks based on genetic algorithms for recycled aggregate concrete," Advances in Materials Science and Engineering, vol. 2013, pp. 680-685, 2013.

[29] F. Khademi, S. M. Jamal, N. Deshpande, and S. Londhe, "Predicting strength of recycled aggregate concrete using artificial neural network, adaptive neuro-fuzzy inference system and multiple linear regression," International Journal of Sustainable Built Environment, vol. 5, no. 2, pp. 355-369, 2016.

[30] İ. B. Topçu and M. Sarıdemir, "Prediction of compressive strength of concrete containing fly ash using artificial neural networks and fuzzy logic," Computational Materials Science, vol. 41, no. 3, pp. 305-311, 2008.

[31] A. Behnood and E. M. Golafshani, "Predicting the compressive strength of silica fume concrete using hybrid artificial neural network with multi-objective grey wolves," Journal of Cleaner Production, vol. 202, pp. 54-64, 2018.

[32] F. Deng, Y. He, S. Zhou, Y. Yu, H. Cheng, and X. Wu, "Compressive strength prediction of recycled concrete based on deep learning," Construction and Building Materials, vol. 175, pp. 562-569, 2018.

[33] R. Eberhart and J. Kennedy, "A new optimizer using particle swarm theory," in Proceedings of the Sixth International Symposium on Micro Machine and Human Science, Nagoya, Japan, October 1995.

[34] P. Ramdya, R. Thandiackal, R. Cherney et al., "Climbing favours the tripod gait over alternative faster insect gaits," Nature Communications, vol. 8, no. 1, pp. 1-11, 2017.

[35] L. Wang, C. Li, J. Qiu, K. Wang, T. Liu, and H. Li, “Treatment and effect of loess metro tunnel under surrounding pressure and water immersion environment," Geofluids, vol. 2020, Article ID 7868157, 2020.

[36] Z. Hu, K. Du, J. Lai, and Y. Xie, "Statistical analysis of influence of cover depth on loess tunnel deformation in NW China," Advances in Civil Engineering, vol. 2019, Article ID 2706976, 2019.

[37] L. Deng, W. Fan, S. Liu, Y. Chang, Y. Dai, and Y. Li, "Quantitative research and characterization of the loess microstructure in the Bai Lu tableland, Shaanxi Province, China," Advances in Civil Engineering, vol. 2020, Article ID 3681382, 2020.

[38] L. Guoming, Weimin, Cheng, Lianjun, and Chen, "Investigating and optimizing the mix proportion of pumping wetmix shotcrete with polypropylene fiber," Construction and Building Materials, vol. 150, pp. 14-23, 2017.

[39] A. Mohajerani, D. Rodrigues, C. Ricciuti, and C. Wilson, "Early-age strength measurement of shotcrete," Journal of Materials, vol. 2015, no. 1, pp. 1-10, 2015.

[40] G. Zhou, W. Cheng, and S. Cao, "Development of a new type of alkali-free liquid accelerator for wet shotcrete in coal mine and its engineering application," Advances in Materials Science and Engineering, vol. 2015, Article ID 813052, 2015.

[41] W. Nie, X. Ma, W. Cheng et al., "A novel spraying/negativepressure secondary dust suppression device used in fully mechanized mining face: a case study," Process Safety and Environmental Protection, vol. 103, pp. 126-135, 2016.

[42] P. Li, Z. Zhou, L. Chen, G. Liu, and W. Xiao, "Research on dust suppression technology of shotcrete based on new spray equipment and process optimization," Advances in Civil Engineering, vol. 2019, pp. 1-11, 2019.

[43] R. Irmler and J. Buchner, "Influence of geotechnical parameters on dust potential of sulphate bearing clay-siltstone in tunnelling works," Tunnelling and Underground Space Technology, vol. 104, Article ID 103537, 2020.

[44] L. Chen and G. Liu, "Airflow-dust migration law and control technology under the simultaneous operations of shotcreting and drilling in roadways," Arabian Journal for Science and Engineering, vol. 44, no. 5, pp. 4961-4969, 2019.

[45] Q. Liu, W. Nie, Y. Hua, H. Peng, and Z. Liu, "The effects of the installation position of a multi-radial swirling air-curtain generator on dust diffusion and pollution rules in a fullymechanized excavation face: a case study," Powder Technology, vol. 329, pp. 371-385, 2018. 